\title{
PROBLEEME SAMASTAMISEGA: SALTOVERE JA KOWREVERE ${ }^{1}$
}

\author{
MARJA KALLASMAA
}

\begin{abstract}
Annotatsioon. Kirjutises vaadeldakse vanades dokumentides esinevate kohanimede seostamist tänapäeva kohanimedega kahe näite, 1319. aastast pärit külanimede üleskirjutuste Saltovere ja Kowrevere põhjal, mis identifitseeritakse erinevalt senisest traditsioonist Läänemaal Hanila kihelkonnas olevate külanimedega Salevere ja Kõera. Nimedele Salevere, Kõera, Koeri ja Koora antakse ka võimalikud apellatiivsed vasted.
\end{abstract}

Võtmesõnad: eesti keel, külanimed, kohanimede identifitseerimine, etümoloogia

Kohanimede varasemad kirjapanekud aitavad hinnata kohanimede vanust ja varasemat kuju, seetõttu on nad etümologiseerimisel väga tähtsad. Varaste dokumentide puhul tekib aga küsimusi, millise tänapäevase kohanimega dokumendis leiduvat kirjapanekut ühendada. Siin jääb paljugi oletuste varale.

1319. aastast pärit ürikus on mainitud, et Johannes Buxhöwdenile (Iohannis Bixdehovede) kuuluvad Saltovere ja Kowrevere küla, mis ta on ostnud Saaremaa piiskopi Conradi vahendusel ja piiskop Hartungi kinnitusel (LUB II: 667). Friedrich von Buxhöwden (1851: 114) on sellest teinud järelduse, et nime Saltovere tuleb õieti lugeda Sallavere ja et see eestlaste küla on olnud aluseks Saaremaa Kaali mõisale, mille saksakeelne nimi on Sall. Seda Buxhöwdeni hüpoteesi kordab ka Baltisches Historisches Ortslexikon (BHO: 529). Dokumendis endas ei ole mainitud, kus nimetatud külad asuvad.

1930ndail (õieti vist 1938) määrati Kaali kraatrist läänes asuvale külale nimeks Salavere, mida Herbert Ligi on pidanud pseudoajalooliseks, Buxhöwdeni poolt lansseeritud külanimeks. Ta ütleb Buxhöwdeni hüpoteesi kohta lausa: „Pole aga ei otseseid ega kaudseid andmeid, mis seda

${ }^{1}$ Uurimistööd on rahastanud SF0050037s10 ja ETF9367. 
seisukohta toetaksid" (Ligi 1984: 292). Oma artiklis H. Ligi dokumendile endale ei viita, kuid olles läbi vaadanud XVII-XIX sajandi allikad, kus kõnealune külanimi ei esinenud, on ta kindlaks teinud, et praeguse Salavere küla kohal oli XVIII sajandil kaks Sindla hajatalu.

H. Ligi seisukohal on kaks nõrka kohta. Esiteks, kui kunagise eestlaste küla asemele asutati mõis, võidi küla täielikult hävitada ja säilis ainult nime esimene pool, mis sai mõisanimeks. Teine ebakoht on see, et H. Ligi on vältinud Buxhöwdenile aluseks olnud allikat. Esimene nõrkus muidugi jääb. Teise puhul tekib küsimus: miks? Kas mitte seetõttu, et dokumendis nimetatud Saaremaa piiskop oli tegelikult Saare-Lääne piiskopkonna piiskop, kellele tol ajal kuulus ka Lääne-, Pärnu- ja isegi Harjumaa osi ning mainitud külad ei pruukinudki olla Saaremaal. Kust võiks neid veel otsida?

Praegu on Eestis kaks Salevere-nimelist küla: üks Salevere Pärnumaal Koonga vallas (Mih) ja teine Salevere Läänemaal Hanila vallas (Han). Tundub, et üks neist võiks olla Saltovere järglane.

Pärnumaa Salevere kohta on leidunud järgmised kirjapanekud: 1534 Szallover, 1543 Sallover (küla Koonga ametkonnas), 1624 Sallafer (küla Koonga mõisa all, külas talupoeg Sallastfer Juergen), 1638 Sallufer, 1798 Sallafer (Stackelberg 1928: 156, 225; Rev 1624 PL: 16-17; Rev 1638 II: 52; Mellin).

Läänemaa Salevere kohta on teada: 1539 Perto Sallover (talupoeg Ullaste külas), 1591 Saleuere By, 1686 Saloferby, 1798 Sallefer (Stackelberg 1928: 131; EAA: 1.2.932: 85, L 80; EAA: 1.2.941: 1002, L988p; Mellin).

Nende kirjapanekute järgi on nimed peaaegu ühevanused, kuid Pärnumaa (sel ajal küll ka Läänemaa alla arvatud, Koonga ametkonda kuuluv) Szallover/Sallover on märgitud külana, samal ajal kui loodepoolne Läänemaa nimi on talupoja lisanimi, mis võis tähendada talu. Üldiselt on vere-nimed küll külanimed, kuid hilisema materjali põhjal on Gea Troska näidanud, et Lääne-Eestis võis vere-lõpuline olla ka hajatalu nimi, sageli võis ette tulla, et samasuguse algusosaga vere-lõpuline ja pere-lõpuline nimi esinesid lähestikku asuvatel hajataludel või samal talul eri aegadel (Troska 1995: 30).

Vaatleme dokumendi teist nime, Kowreveret, mille BHO (: 238) samastab Pärnumaal Varbla vallas (Var) asuva Koeri külaga. Koeri kirjapanekud: 1320 Kogerevere (Bfl R: 276, BHO: 238 ekslikult Kogervere), 1543 Korakuyla Iuri (üksjalg Koonga vakuses), 1782 Koeiri, 1796 Koiri 
(Bfl R: 226, (Bfl I: 35); Stackelberg 1928: 155; EAA 1864.2.IV-9: 317, L 300; Mellin). Küla asub Varbla kihelkonna idaservas üksikuna küllalt kaugel teistest küladest, nagu ka Mihkli kihelkonnas asuv Salevere, mõlemad kuulusid Koonga ametkonda. Kahtlane on Kogerevere samastamine Koeri külaga. 1320. aasta dokumendis on mainitud veel Normes (Nurmsi), Wattele (Vatla), Hovestette (Hoveselle) (Hõbesalu), mis kõik asuvad Lihula diötseesis Karuse kihelkonnas lähestikku (Bfl I: 35). Selle dokumendi järgi võiks pigem oletada, et Kogerevere puhul on tegemist tänapäeva Koora külaga (sks Koeraküla), mis asuks mainitud küladega ühes piirkonnas. Tegemist on samuti vana külaga. Kahtlemata käivad Koora kohta ülestähendused 1565 Karefer by, 1591 Karauer By ja 1726 Karrefer (EAA 1.2.932: 14, L 12; EAA.1.2.941: 184, L 169; Rev 1725/26 Lä: 118), ehkki kaardimaterjali puudumisel ei saa seda täie kindlusega väita. Seletuseta jääb esisilbi $a$ kirjapanekutes, kuid nii küla asend revisjonides kui ka Koora asend maastikul toetavad seda samastust. 1782 on küla kirja pandud Kaura nime all (EAA 1864.2.IV-9: 263, L 252).

Seevastu Läänemaal Hanilas on lausa Salevere kõrval Kõera küla, mille edasised kirjapanekud on järgmised: 1591 Körwer By, 1689 Köere By, 1798 Koiri (EAA: 1.2.932: 86, L 80p; EAA: 1.2.941: 1002, L 988p; Mellin). Arvatavasti on nimega seotud 1539. aasta kirjapanekud Ian Kere ja Andres Kere (Stackelberg 1928: 131). Kõikides revisjonides on Salevere ja Kõera kõrvuti, tõenäoliselt just need külad Läänemaal on Saltovere ja Kowrevere, mida 1319. aastalgi koos mainitakse.

Kui nii, siis oli Kõera küla kujunenud vahepeal kaheks üksjalakohaks, mis olid märgitud Ullaste küla järel. Ullaste on tõenäoliselt XVI sajandil tekkinud nimi, veel 1534 on külanimena märgitud Hempo, kus oli talupoeg Ollest Otte. 1539 on külanimeks Ullas ja esimesena on mainitud kümnikut nimega Hempo (Stackelberg 1928: 131, 211). 1565. aastast on kirjas aga wllas Kallaffer by, wllas och MoyßerBw (?) (EAA 1.2.932: 12, L 10), viimane kuulus siis Lihula kloostrile.

Nagu öeldud, revisjonides on Salevere ja Kõera kõrvuti, nagu on nad maastikulgi. Oleks loogiline oletada, et 1319 mainitud külad olid samuti kõrvuti. Teisalt asusid nii Varbla Koeri kui ka Mihkli Salevere ühes ja samas Koonga ametkonnas.

Nime Salevere lähtekohaks võiks olla salu, kuigi Lauri Kettunen (1955: 240, 313, 317) on esmaseks võimaluseks pidanud siiski sõna sala või sale, näiteks sale mets 'hõre mets'. 
Koeri aluseks võiks oletada sõna koer (koir), viimane võis olla isikunimi, mis esines veel 1726 ees- ja lisanimena Lihula kihelkonnas: Niggola Koirri, Koera Jak (Rev 1725/26 Lä: 111). Võimalik, et see eesnimi on Gregoriuse mugand, mis on rahvaetümoloogiliselt seostatud sõnaga koer (koir). Tänapäeva nime oe-line kuju välistab $\ddot{o}$-lise või $\tilde{o}$-lise tõlgenduse võimaluse.

Koora lähtekohaks (kui sellega samastada Kogerevere) on võimalik oletada kas sõna koger, mis võinuks esineda isikunimena, või isikunime Kogge. Hiiumaal on Kogri küla: 1709 Kåckero by, 1726 Koger; Läänemaal Kokri: 1689 Kockry Byy (Kallasmaa 2010: 88; EAA 1.2.941: 348, L 339p). Ka siin on väike võimalus oletada Gregoriuse mugandit.

Kõera jääb etümoloogiliselt ebaselgeks, kirjapanekute põhjal võib võrdluseks tuua võimalikud vasted kõer 'kõver' (Wiedemann), kõrb : kõrve 'suur mets, liivane põllumaa, karjamaa' ja kõre 'hõre, suurte puudega mets; pikk sirge kuusk või mänd' (EMS IV,17: 273-274) ning isikunime Kerro: 1534 Hans Kerropoyck (Stoebke 1964: 37).

\section{Kirjandus}

Bff $=$ Est- und Livländische Brieflade. I Th. Dänische und Ordenszeit. Bd. 1, Eine Sammlung von Urkunden zur Adels- und Gütergeschichte Est- und Livlands, in Uebersetzungen und Auszügen, 1856; Bd. 2, Register zum ersten Bande, 1857. Hrsg. von Friedrich Georg von Bunge und Robert von Toll. Reval: Kluge und Ströhm.

BHO $=$ Baltisches historisches Ortslexikon. Teil I, Estland (einschließlich Nordlivland), 1985. Begonnen von Hans Feldmann. Hrs. von Heinz von zur Mühlen. (= Quellen und Studien zur baltischen Geschichte 8/I.) Köln-Wien: Böhlau Verlag.

Buxhöwden, Friedrich von 1851. Zweite Fortsetzung von des Herrn Hofraths von Hagemeister „Materialien zur Gütergeschichte Livlands”, enthaltend Beiträge zu einer älteren Geschichte d. Oeselschen Landgüter u. ihrer Besitzer / K. F. C. von Buxhövden. Riga: Kymmel.

EMS = Eesti murrete sõnaraamat. IV, 17 (kõhvits-kähür), 2005. Toim. Evi Juhkam, Mari Kendla, Piret Norvik, Jüri Viikberg. Eesti Teaduste Akadeemia, Eesti Keele Instituut. Tallinn: Eesti Keele Sihtasutus.

Kallasmaa, Marja 2010. Hiiumaa kohanimed. Toim. Eevi Ross. Tallinn: Eesti Keele Sihtasutus.

Kettunen, Lauri 1955. Etymologische Untersuchung über estnische Ortsnamen. (= Suomalaisen Tiedeakademian Toimituksia. Sarja B, 90, 1.) Helsinki. 
Ligi, Herbert 1984. Kaali katastroof ja Püha kihelkonna kohanimed. - Keel ja Kirjandus 5, 286-293.

LUB = Liv-, Esth- und Curländisches Urkundenbuch nebst Regesten. Bd. 2, 1301-1367, 1855. Hrsg. von Friedrich Georg von Bunge. Reval: Kluge und Ströhm.

Mellin, Ludwig August 1794-1798. Atlas von Liefland, oder von den beyden Gouvernementen u. Herzogthümern Lief- und Ehstland und der Provinz Oesel. Riga und Leipzig.

Rev 1624 PL = Das Pernauer Land 1624. Hrsg. Oleg Roslavlev. Hefte zur Landeskunde Estlands. Heft 2, 1967. München.

Rev 1638 II = Die Revision Livlands 1638. Estnisches Siedlungsgebiet II. Hrsg. Oleg Roslavlev. Hefte zur Landeskunde Estlands. Heft 4, 1969. München.

Rev 1725/26 Lä = Eestimaa 1725.-1726. a. adramaarevisjon. Estländische Hakenrevision von 1725 bis 1726. Läänemaa. Allikpublikatsioon. 1990. Eesti Ajalooarhiiv, Tartu Ülikool. Tallinn: Tartu Ülikool.

Stackelberg, Baron F. 1928. Das älteste Wackenbuch der Wiek (1518-1544). Õpetatud Eesti Seltsi Aastaraamat / Sitzungsberichte der Gelehrten Estnischen Gesellschaft 1927. Tartu, 78-254.

Stoebke, Detlef-Eckhard 1964. Die alten ostseefinnischen Personennamen im Rahmen eines urfinnischen Namensystems. Nord- und osteuropäische Geschichtsstudien. Band IV. Hamburg: Leibniz-Verlag.

Troska, Gea 1995. Talunimed läbi aegade. Tallinn: Teaduste Akadeemia Kirjastus.

Wiedemann, Ferdinand Johann 1973. Eesti-saksa sõnaraamat. Neljas, muutmata trükk teisest, Jakob Hurda redigeeritud väljaandest [1893]. Tallinn: Valgus.

EAA 1.2.932 = Lihula lääni ja Hiiumaa vakuraamatud

EAA 1.2.941 = Läänemaa adramaarevisjon

EAA 1864 = Eestimaa kubermangu revisjonilehtede kollektsioon 


\title{
Problems with identification: Saltovere and Kowrevere
}

\author{
Marja Kallasmaa
}

Identification of place names in earlier (older) documents involves a considerable degree of speculation. The article deals with the establishment of links between place names in old documents and present-day place names; two examples from 1319 have been chosen - Saltovere and Kowrevere. They are identified as Salevere and Kõera (western Estonia, Hanila parish), which is different from the traditional interpretation as Sall, in Estonian Kaali (Saaremaa, Püha parish). Differently from L. Kettunen, Salevere is identified as salu 'grove, coppice, wood' + formative -vere and Kõera as kõer 'crooked, curvy' or kõrb: kõrve 'forest; sandy land' or kõre 'tall tree or a wood of such trees', or the personal name Kerro.

Keywords: Estonian language, village names, identification of place names, etymology

\section{Marja Kallasmaa}

keeleajaloo ja -teaduse osakond

Eesti Keele Instituut

Roosikrantsi 6

10119 Tallinn

Marja.Kallasmaa@eki.ee 